\title{
Efficient GIS-based model-driven method for flood risk management and its application in central China
}

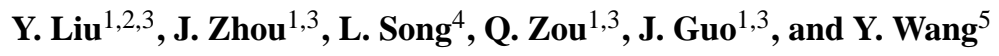 \\ ${ }^{1}$ School of Hydropower and Information Engineering, Huazhong University of Science and Technology, \\ Wuhan, 430074, China \\ ${ }^{2}$ School of Electrical and Electronic Engineering, Hubei University ofTechnology, Wuhan, 430068, China \\ ${ }^{3}$ Hubei Key Laboratory of Digital Valley Science and Technology, Huazhong University of Science and Technology, Wuhan, \\ 430074, China \\ ${ }^{4}$ Laboratory of Numerical Modeling Technique for Water Resources, Department of Water Resources and Environment, Pearl \\ River Water Resources Research Institute, Guangzhou, 510623, China \\ ${ }^{5}$ School of Engineering and Technology, Hubei University of Technology, Wuhan, 430068, China
}

Correspondence to: J. Zhou (jz.zhou@ mail.hust.edu.cn)

Received: 13 March 2013 - Published in Nat. Hazards Earth Syst. Sci. Discuss.: 24 April 2013

Revised: 2 January 2014 - Accepted: 17 January 2014 - Published: 21 February 2014

\begin{abstract}
In recent years, an important development in flood management has been the focal shift from flood protection towards flood risk management. This change greatly promoted the progress of flood control research in a multidisciplinary way. Moreover, given the growing complexity and uncertainty in many decision situations of flood risk management, traditional methods, e.g., tight-coupling integration of one or more quantitative models, are not enough to provide decision support for managers. Within this context, this paper presents a beneficial methodological framework to enhance the effectiveness of decision support systems, through the dynamic adaptation of support regarding the needs of the decision-maker. In addition, we illustrate a loose-coupling technical prototype for integrating heterogeneous elements, such as multi-source data, multidisciplinary models, GIS tools and existing systems. The main innovation is the application of model-driven concepts, which put the system in a state of continuous iterative optimization. We define the new system as a model-driven decision support system (MDSS ). Two characteristics that differentiate the MDSS are as follows: (1) it is made accessible to non-technical specialists; and (2) it has a higher level of adaptability and compatibility. Furthermore, the MDSS was employed to manage the flood risk in the Jingjiang flood diversion area, located in central China near the Yangtze River. Compared with traditional solutions, we believe that this model-driven method is efficient,
\end{abstract}

adaptable and flexible, and thus has bright prospects of application for comprehensive flood risk management.

\section{Introduction}

Flood disasters are among the most frequent and devastating types of disasters in the world (International Federation of Red Cross and Red Crescent Societies, 1998). In China, up to two-thirds of the land subject to different types and levels of risk from river and coastal flooding (Feng et al., 2001; Wang et al., 2004). Within this context, we are facing a paradigm shift in dealing with flood issues from flood protection towards flood risk management (Evers et al., 2012). Moreover, given the growing complexity and uncertainty in many decision situations of flood risk management, personal experience and single models are not enough to provide decision support for managers. Therefore, comprehensive flood risk management has widely been used in flood insurance, flood plains management, disaster evacuation, disaster warning, disaster evaluation, flood influence evaluation, and improving the public's flood risk awareness and understanding of flood disasters (Zeng et al., 2007; Ray, 2007; EscuderBueno et al., 2012; Chen et al., 2011; Schinke et al., 2012; Li et al., 2012; Evers et al., 2012). 
Traditionally, tight-coupling integrations of one or more quantitative models were the dominant of the flood risk management approaches. However unique aspects of flood risk management problems require a special approach for dynamic adaptation of support regarding the needs of the decision-maker. Bijan et al. (1997) believed that there is an additional intelligent "adaptation" component that can achieve absolute adaptation. We cannot prove that this assumption is feasible, but our approach is to ensure that the algorithms and models are in a loose-coupling framework, e.g., can be easily reconstructed to accommodate the demand. Over the past $10 \mathrm{yr}$, we have focused on the need for flood control by integrating remote sensing and GIS techniques with qualitative or quantitative models, including hydrologic analysis, flood simulation, flood risk analysis, and disaster assessment (Zou et al., 2012a, b; Guo et al., 2011; Song et al., 2011b).

In recent years, the purpose of our research has increasingly become to propose a universal approach for flood risk management by the model-driven method, which provides an accessible interface to non-technical specialists, such as managers. Furthermore, the method is intended for repeated use in the same or a similar decision situation (Power and Sharda, 2007). In order to achieve these objectives, many research studies have been carried out on this topic. They can be outlined as follows: (1) model-driven method for flood risk management; (2) loose-coupling framework of hardware and software system; (3) multidisciplinary optimization and mathematical programming models.

For the reader's convenience, the remainder of this paper is organized as follows:

- Section 2 provides an overview and analysis of past model-driven method research, then identifies research challenges related to behavioral and technical aspects of implementing and using the method for flood risk management;

- Section 3 defines our model-driven methodological framework and proposes its systems life cycle for designing and developing a MDSS;

- Section 4 illustrates the loose-coupling technical prototype through identifying and incorporating the key components for our model-driven method;

- Section 5 presents how we adopt the method in the Jingjiang flood diversion area, where we are commissioned by the government to assist the operations of engineering and controlling the flood risk;

- Section 6 demonstrates the benefits of our modeldriven method through comparing with some traditional solutions;

- The final section provides a summary of observations and recommendations for future directions of research in model-driven methods for flood risk management.

\section{Background}

\subsection{Overview of model-driven method research}

Nowadays, developing applications for non-technical end users is becoming increasingly complex, as they want to access these applications everywhere, at every moment of the day and night and with many different devices (Gates, 2008). On the other hand, the model which address the decision support problem for flood risk management is becoming multidisciplinary (as discussed last section). Therefore, economists, geographers, water resource specialists, operation researchers and management scientists had to integrate their respective models together to support managers' decision-making and planning.

Traditionally, by using object-oriented software engineering, many computer programs, which are based on a tightly coupled integration of models and interface, is presented to help the decision-maker make effective decisions. It is commonly believed that this way can guarantee the stability and high performance of the system. However, given the growing complexity and uncertainty in many decision situations of flood risk management, we need a special approach to the dynamic adaptation of support regarding the needs of the decision-maker. This approach needs to provide an integration platform for multidisciplinary models, not subject to geographical distribution, research area, development language, software tool and other constraints, and to guarantee that the system has a higher level of adaptability and reusability. Taking the above factors into consideration, the focus of the study will be divided into two parts: (1) modelcentric decision-making process ensures DSS adaptability; (2) loose-coupling implementation ensures DSS flexibility.

Model-driven method research can be distributed in two aspects. The first is as DSS foundations research, which has been one of the most important topics since 1969 (Power and Sharda, 2007); the method uses algebraic, decision analytic, financial, simulation, and optimization models to provide decision support. The second, software engineering research, model-driven method (or model-driven engineering) and recent trend, whose main proposal is to focus on models rather than on computer programs (Bézivin, 2004). And it is being increasingly applied to enhance system development from perspectives of maintainability, extensibility and reusability (Mehmood and Jawawi, 2013). With the rapid development within the field of Web service technologies and service-oriented computing, the model-driven method has been widely used in the area of business process management (Watson, 2008).

Eom (2003) identified a wide variety of DSS applications reported in the academic literature. There are more than 1800 related articles, and many of them focused on our research direction with good results. However, by querying this large number of scientific papers, we noticed that the modeldriven research within the field of natural disasters is at the 
beginning stage, especially the rare loose-coupling framework for resolving behavioral and technical challenges. Furthermore, we believe that this approach would address the issues raised by the managers, end users and scientists from different disciplines. Therefore, we started a study to validate this hypothesis.

\subsection{Behavioral and technical challenges}

Behavioral and technical research on model-driven methods needs to address many unresolved issues, which is identified by Power et al. (2007) as follows: (1) construction of specific quantitative models; (2) storage and retrieval of data needed by different types of models; (3) communication of parameters among models and other DSS (decision support system) components; (4) multi-participant interaction in model use and value elicitation; (5) impact of user interface design alternatives on model-driven DSS effectiveness and ease of use; and (6) building, deploying and using model-driven DSS. In addition, with the remarkable improvement of spatial representation research, there is a new challenge associated with the integration of geographic information systems (GISs) with multidisciplinary models (Merz et al., 2010).

\section{Model-driven methodological framework for flood risk management}

We define our model-driven method as a methodology that supports human decision-making judgements by a loosecoupling platform with multidisciplinary optimization and mathematical programming models. In this section, we will describe the behavioral aspects of this method, i.e., how it works. The technical aspects of implementation will be discussed in the Sect. 4.

All in all, the general types of models used in a modeldriven DSS is numerous. They include algebraic and differential equation models; various decision-analysis tools, including analytical hierarchy process, decision matrix and decision trees; multi-attribute and multi-criteria models; forecasting models; network and optimization models; Monte Carlo and discrete event simulation models; and quantitative behavioral models for multi-agent simulations. Therefore, the focus of research work is placed on how to provide a simplified representation of a situation that is understandable to a decision-maker (Power and Sharda, 2007).

The main innovation of this paper is that our method makes the DSS in a continuous-integrated state (see Fig. 1), which means: (1) the system platforms and decision-making processes are iterative optimization; (2) the latest client will be published simultaneously in real time. In other words, based on the loose-coupling platform, these systems can provide the dynamic adaptation of support regarding the needs of the decision-maker. In order to achieve the continuousintegrated state, the systems life cycle is designed to be a novel double-loop optimization structure, which consists of two parts: the technical-loop, and the behavioral-loop (see Fig. 2). The technical-loop is used to build deployable software at any time, which can provide a dynamic integration platform for data, models, decision-making processes and the existing systems. We can illustrate the loose-coupling technical prototype in the following sections. Interacting with the technical-loop, the behavioral-loop is developed for connecting the user groups, including managers, practitioners and scientists from different disciplines. Scientists can register their models to address a new decision-making task at any time, or improve the adaptability of old models for reusability problems. Practitioners can customize the decision process by combining models, and design the client by system interface (i.e., Interface Service, which will be referred to in Sect. 4.5). Managers, who have the right to make decisions, can use the common client or the recommended client by practitioners. Furthermore, the feedback mechanisms make the requirements clearer, and systems are more reasonable and reliable.

\section{Loose-coupling technical prototype for the model-driven method}

\subsection{Overall framework}

In this section, we will illustrate a technical solution, i.e., loose-coupling prototype, for the model-driven development through identifying and incorporating the key components. All in all, loose-coupling is the concept typically employed to deal with the requirements of scalability, flexibility, and fault tolerance. The aim of loose coupling is to minimize dependencies. When there are fewer dependencies, modifications to or faults in one system will have fewer consequences on other systems. On the other hand, it makes the joint analysis of cross-regional models possible, e.g., mechanical experts in Beijing address the risk assessment, at the same time, hydrodynamic experts in Wuhan deal with the damage estimation of flood routing.

The software is worked in a simple and clear structure. Client is only responsible for the function of user interaction, which collects user's command by events of various controls, then translates the order into an XML data stream and pushes it to the central communication service in the service layer; the load balancing server deals with this command and assigns it to the right server. Finally, the process ends in the database changes. Therefore, scientists can register their models into the service layer for easy uses, and managers can get results via a beautiful interface.

The software architecture is composed of a three-layer structure (see Fig. 3), which is identified as follows: (1) a base layer, supporting the distributed systems, including networks, softwares, operating systems, databases, etc.; and (2) a services layer, for service-oriented specific functionalities. 


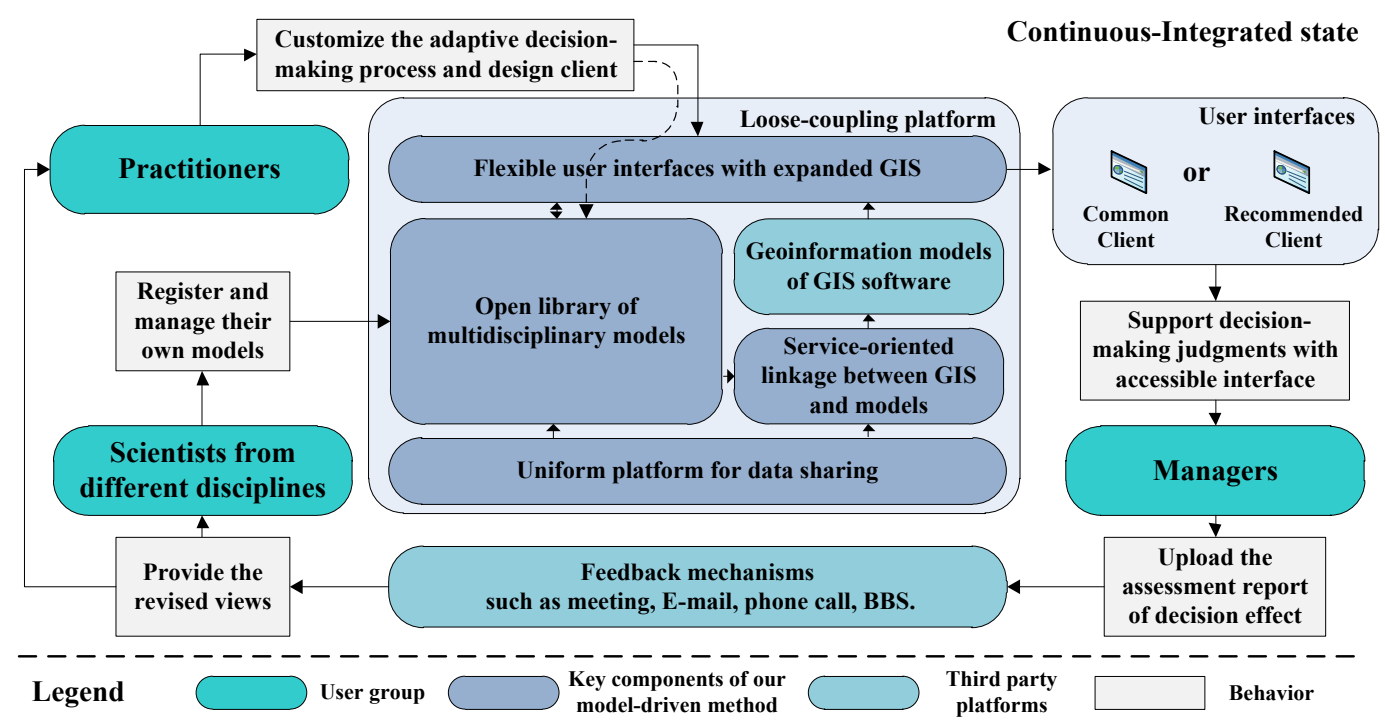

Fig. 1. Behavioral aspects of the model-driven method for flood risk management.

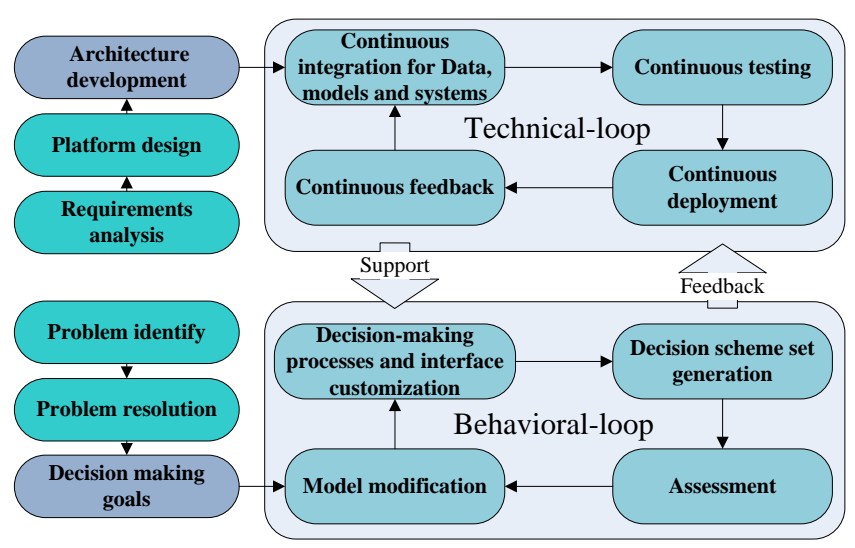

Fig. 2. Systems life cycle for model-driven methodological framework.

Among them, a service provider publishes its description of service and interface in formation to the service registry. A service requester will find relevant service from this registry and then establish a link to invoke that service; and (3) implementation layer. It provides web service applications to implement the service-oriented architecture (SOA). Details on this layer are discussed in later sections (see Sect. 4.3). In addition, The Services layer or its implementation layer can also project itself onto an operational layer, which consists of workflow components of publishing, discovery, composition, binding and execution (Hu et al., 2011).

We define the loose-coupling DSS as a model-driven decision support system (MDSS). In a MDSS, first, a uniform data platform (as database service) is presented to share multi-source data. Next, an open library (as multidisciplinary model service) is presented to integrate cross-platform mod- els. A universal linkage (as GIS Service) between GIS and models is then presented by use of service-oriented approach. Finally, a flexible interface system (as interface service) is presented to help practitioners customize the application for decision-makers.

\subsection{Uniform platform for data sharing}

A GIS-based MDSS needs to deal with numerous raw data for decision-making, which includes the traditional structured data and other special data. The special data originate from remote sensing images, live video, live audio, sensor stream and so on. In essence, it is multi-modal data with the characteristics of semi-structured or unstructured.

Many challenges are associated with the integration of the multi-source data. They include efficient structured treatment, heterogeneous data fusion, and cross-platform communication. By considering the specific problem in distributed systems and following the design concepts of SOA, this paper proposes a common unified data platform, which is divided into two parts, monographic data support and geographic data support. We will focus on the integration of these two in the following section. Finally, for different sources of the data, the database service provides various types of packaged web services interface to enable efficient interaction between the model library and user interface (see Fig. 4).

\subsubsection{Similarity-based monographic data integration}

The discrepancies in multi-source data occur both during eliminating duplicates from semantic overlapping sources and during combining complementary data from different sources (Schallehn et al., 2003). A similarity-based data 


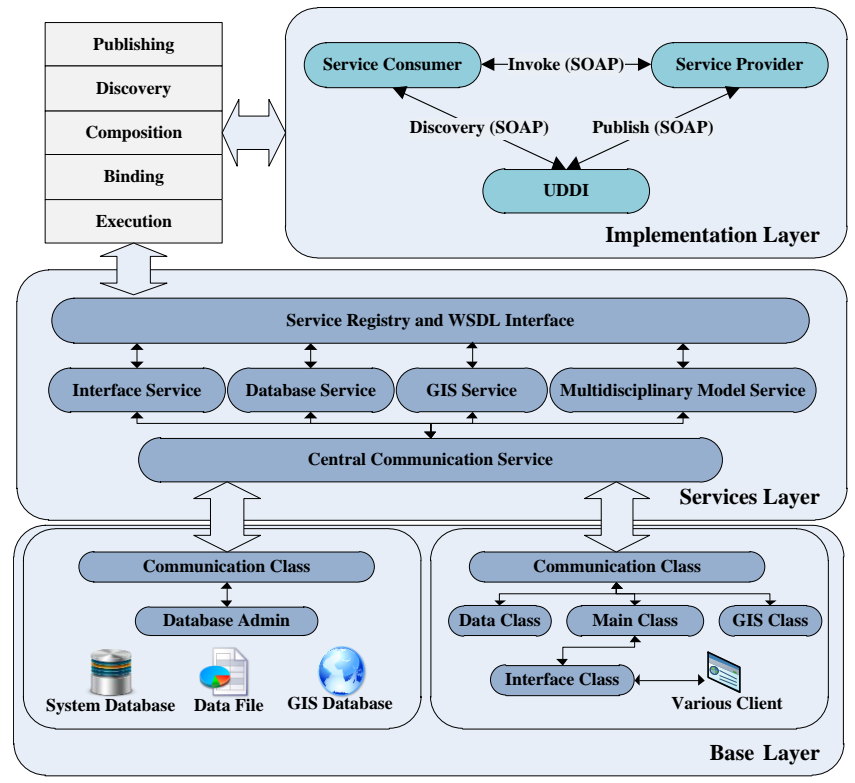

Fig. 3. Loose-coupling framework for the model-driven method.

integration model (SDIM) is used to deal with discrepancies in multi-source data. The discrepancies in structured data can be directly solved by existing operations of common relational database, such as SQL operations like grouping or join. However, for the unstructured or semi-structured data, the integration process will be much more complicated. The processing steps of the unstructured data are as follows:

1. Extracts the features of data, automatically generates the data source configuration file and sets the index item;

2. Supported by XML document conversion model, preprocesses the raw data in order to get the proposed keyword, and generates the XML index document. In XML, contexts are given through element and attribute names, and relationships by organizing data into trees and subtrees, and through id references;

3. Groups the XML information with similarity measures by its attribute and logical combination. The similarity formula is determined by the user preference, which will not be discussed here. It can be a simple threshold value or a complex comprehensive approach;

4. Adds formatting information, and uses the relational database management software operations to sort the processed data.

\subsubsection{Demand-oriented geographic data integration}

The data for representing geology is diverse, heterogeneous and multi-source, so it is difficult to identify the correlation

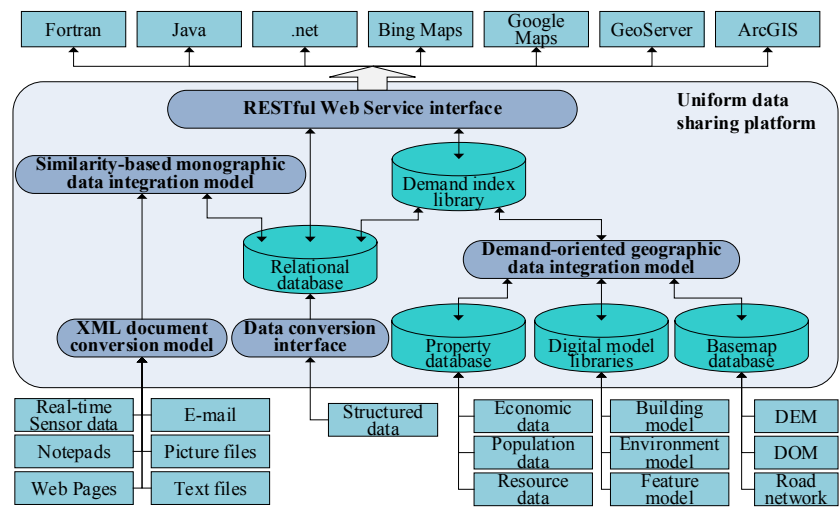

Fig. 4. Architecture of the uniform data sharing platform.

between them. The traditional integration methods are dedicated to the technical problems of data integration performance (Wu et al., 2005), such as data transmission and data query. In this paper, a demand-oriented geographic data integration model is used to establish a logical association between these data. First of all, the demand for geographical data in GIS-based DSS is divided into two, spatial analysis and visual simulation. Then the proposed model builds the data schema from multisource data in a stepwise manner and involves six steps: (1) digitizing various geological data using existing software systems like ArcGIS or Microsoft SQL Server; (2) registering and filling in the details; (3) making sure they have uniform dimensions and data types; (4) building a hierarchical link list for each demand of models; (5) creating the geographic cache; and (6) modifying the index information for service access.

\subsection{Open library of optimization and mathematical programming models}

In this section, we will describe how we address the loosecoupling integration problem for multidisciplinary model.

The service-oriented architecture (SOA) is employed to solve the integration problems. In a SOA, each model can be published as a service, and can communicate with another model even though it has a different underlying operating system. These services are virtually unrelated functional units, but loose-coupling spread over interconnected networks (Hu et al., 2011). It uses the Web Service Description Language (WSDL) for describing services; a mechanism called Universal Description Discovery and Integration (UDDI) for service registry and service discovery; then the simple object access protocol (SOAP) for exchange of messages. Web services use XML-based standards as a format.

The implementation layer consists of various web service applications and is used to establish the loose-coupling open library, which accepts heterogeneity and leads to decentralization. The core of the implementation layer is a specific infrastructure, called the enterprise service bus (ESB), that 
allows us to combine the multidisciplinary models in an easy and flexible manner.

It is the responsibility of the ESB to enable managers to call the models' providers supply (see Fig. 5). Depending on the technical and organizational approaches taken to implement the ESB, this responsibility may involve (but is not limited to) the following tasks: providing connectivity; data transformation; (intelligent) routing; dealing with security; dealing with reliability; monitoring and logging; and model composition management; model registry and deposit.

There are two ways for scientists to manage their models, personal management or delegated management. Both methods only need scientists to register models on the server by filling some parameter information. The managers still use an official endpoint, which delegates the real task: when messages arrive, the load balancer sends them to the different physical service providers that it knows about.

\subsection{Service-oriented link between GIS and models}

Regional flood risk, generally considered at the river-basin scale, is a decision-making problem based on physical and socioeconomic conditions (McKinney and Cai, 2002). Spatial representations of the region consist of spatial objects and thematic objects. Spatial objects represent real-world entities, with both geographical and physical, environmental and socioeconomic attributes. Thematic objects represent methods and topics relevant to the spatial objects. Therefore, it is the responsibility of the GIS to represent the real spatial entities and provide spatial analysis and data processing. ArcGIS Server 9.3 is used to provide technical support. The key components can be listed as follows (ArcGIS Resource Center, 2008):

- Mapping service. It serves cached maps and dynamic maps from ArcGIS.

- Geocode service. It finds address locations.

- Geodata service. It provides geodatabase access, query, updates, and management services.

- Globe service. It serves digital globes authored in ArcGIS.

- Image service. It provides access to imagery collections.

- Network analysis service. It performs transportation network analysis such as routing, closest facility, and service area.

- Geometry service. It provides geometric calculations such as buffering, simplifying, and projecting.

- Geoprocessing service. It provides spatial analysis and data processing services.

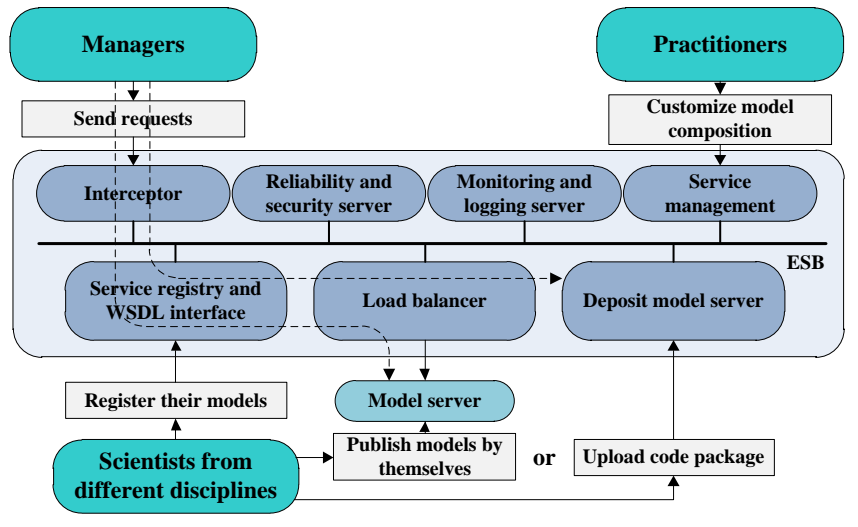

Fig. 5. Open library of optimization and mathematical programming models.

In our model-driven method, the first seven services are used to interact with managers via the GIS-based client to represent the real spatial entities. The last one (i.e., geoprocessing service) is re-developed and integrated into the open library, similar in behavior to a particular model. A geoprocessing service takes the simple data and turns it into something extraordinary: the probable evacuation area for flood hazards, a land cover map going five years back, the risk-sensitive areas after a dam break and so on. Because the service is executed on the server computer, using resources of the server computer, the clients can be lightweight applications, and we do not need to cover the cost of GIS for each individual application.

\subsection{Flexible user interfaces with expanded GIS}

The goal of making model-driven DSS accessible to nontechnical specialists implies that the design and capabilities of the user interface are important to the success within the system (Power and Sharda, 2007). The user interface controls how the user views results and influences how the user understands results and hence influences choices. In our modeldriven method, the clients are lightweight, i.e., they only know how to send packets of simple requests to a server, and show the results through rich controls. Therefore, our client can be developed by a variety of technologies, such as Java Server Pages (JSP), Active Server Page (ASP), Qt, Winform, Windows Presentation Foundation (WPF), Objective$\mathrm{C}(\mathrm{ObjC})$ and so on. In the following section, we have a WPF which is described as an example. Developed by Microsoft, the WPF is graphical subsystem computer software for rendering user interfaces in Windows-based applications. Extensible Application Markup Language (XAML) is employed to define and link various user interface elements. Because XAML is a XML-based language, it can be designed with any text editor. In our model-driven method, the interface service is presented to help practitioners customize the application for decision-makers. 
Via interface service, practitioners can define in how many steps the decision-making process will be completed, then design the control's layout and operation logic for each step. Finally, designs will be translated into text, sent to the server and automatically be generated into corresponding XMAL documents. Decision-makers run the program by downloading clients or landing web pages.

A section on GIS and ArcGIS API (application programming interface) for WPF is employed to create rich desktop applications that utilize the powerful mapping, geocoding, and geoprocessing capabilities provided by the ArcGIS server. Similarly, considered to be a normal control, practitioners can generate instances of GIS by XMAL.

\section{MDSS in the Jingjiang flood diversion area}

\subsection{Basic information about the case study area}

The methodology and the model was performed and tested in the Jingjiang flood diversion area, situated in central China near the Yangtze River. It covers an area of $921.34 \mathrm{~km}^{2}$ (see Fig. 6). It was the first large-scale hydraulic engineering built by the government of the People's Republic of China in 1952. Its main composition contains the incoming flood gate (North Gate), sluice (South Gate) and 208.38 km-long embankments. The project's principal role is to ensure the safety of Jianghan Plain and the Wuhan City. Distinct from developed countries, China's flood diversion area is inhabited by a large number of people, its social and economic cost is very high, with 581.8 thousand people living in eight towns, and the annual production value is USD 700 million. We are commissioned by the government to assist the operation of the engineering management and control the flood risk. The model validation is based on the successful application of this project in 1954.

\subsection{A feasible decision process for flood risk management}

In this section, we will show an example of the feasible decision process (as shown in Fig. 7). Multisource remote sensing images, DEM and hydrological data were coupled with the uniform data-sharing platform. Flood forecasting models can derive the flood process in for two subsequent weeks. Based on hydrodynamic calculations of flood routing simulation models, flood risk assessment and damage estimation models can provide the qualitative or quantitative results, generate various thematic maps to describe the distribution of flood risk, provide guidance on evacuation and assist flood path control for government policy-makers.

\subsection{Hydrology analysis and forecasting}

The flood characteristics, such as the frequency, return period, coefficient of skew, coefficient of variation, and so on,

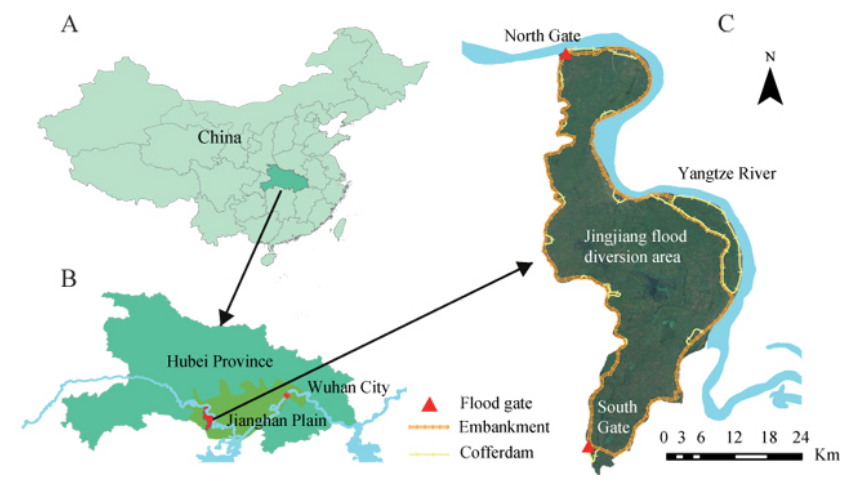

Fig. 6. Location of the study area: (A) map of China, in which the annotated area is Hubei province. (B) Map of Hubei, in which the annotated area is Jianghan Plain, Wuhan City, and the Jingjiang flood diversion area. (C) Map of the Jingjiang flood diversion area.

are analyzed based on historic observed streamflow data. It can provide the basis for choosing those typical flood processes. Meanwhile, to dynamically evaluate the risk and damage of flood hazard in real time, the actual-time flood forecasting model is integrated into our system. At first, we analyze the characteristics of the hydrological system in the sensitive area of flood. Based on this, a conceptual model, the famous Xinanjiang model (Zhao, 1984), is constructed to simulate the flood processes. Currently, the traditional calibration of hydrological models with a single objective cannot properly measure all the behaviors within the system. To circumvent this, an efficient evolution algorithm entitled the multi-objective culture shuffled complex differential evolution (MOCSCDE) algorithm (see Appendix A) is proposed to optimize the model parameters. This algorithm can get better convergence and spread performance, and can significantly improve the calibration accuracy (Guo et al., 2012). These results provide an important basis for studying the mechanism of flood routing.

\subsection{Flood routing simulation}

The flood dynamic routing simulation and the flood risk maps drawing are based on DEM (digital elevation model). The hydrodynamic member of our research team developed a well-balanced Godunov-type finite volume algorithm for modelling free-surface shallow flows over irregular topography with complex geometry. The research results have been published in many academic journals (Song et al., 2011a; Liu et al., 2013). This two-dimensional hydrodynamic model is based on a new formulation of the classical shallow water equation in hyperbolic conservation form (see Appendix B), which describes the state of a flood, such as water depth, velocity, duration and submerged area.

The computational domain was triangulated with 77741 elements, 39389 nodes and 117129 lines. The area of the smallest unit is $4246 \mathrm{~m}^{2}$, the area of the biggest unit is 


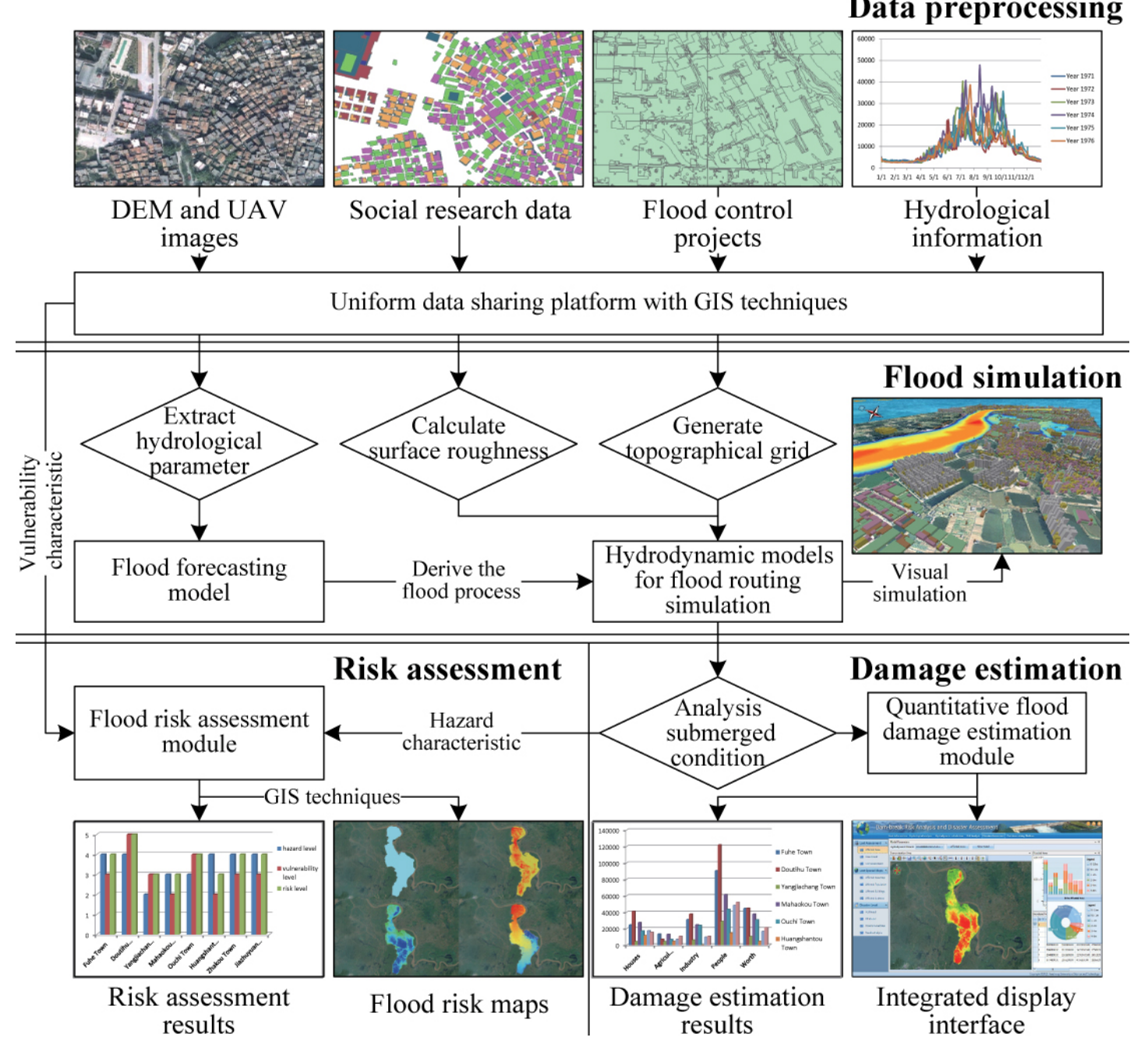

Fig. 7. A feasible decision process for flood risk assessment and damage estimation.

$20000 \mathrm{~m}^{2}$, and length of the shortest line is $69 \mathrm{~m}$. In addition, triangles were more densely organized along the river to ensure the calculation accuracy. The total area of the flood is 2.35 billion $\mathrm{m}^{3}$, and the largest flood diversion flow is $6190 \mathrm{~m}^{3} \mathrm{~s}^{-1}$.

We obtained the bottom elevation of computational grid by bilinear interpolation with high-resolution DEM data, and set the roughness values of each computing unit by land use data. Based on hydrodynamic calculations, the risk mapping module generates various thematic maps to describe the distribution of flood risk, provide guidance on the evacuation and assist control flood path for government policy-makers. Figure 8 shows the simulation results, e.g., the water depth changes within the flood routing, which lasted about $131 \mathrm{~h}$.

\subsection{Flood risk assessment}

As we have seen, flood risk assessment is a synthetic evaluation and consists of many factors; some factors are natural
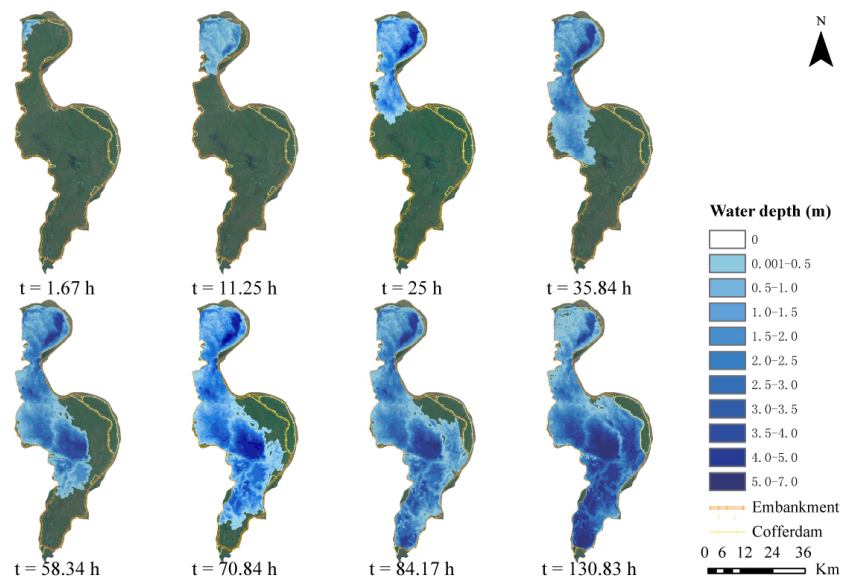

Fig. 8. Filled contours plot of initial and computed water depth given by the present model at time $t=1.67,11.25,25,35.84,58.34$, $70.84,84.17$, and $130.83 \mathrm{~h}$. 
and socioeconomic in various areas, and several of them do not have unified quantitative criteria, which makes the flood risk assessment index system complex and difficult to operate (Du et al., 2006; Li et al., 2008; Jiang et al., 2008). Based on the disaster system theory, which takes into consideration the factors that follow the systematic, quantitative and operability, universality principle, the primary flood risk assessment index system of a flood diversion district is established. According to local investigations, references to historical information, public participation, expert judgments and so on (Du et al., 2006; Li et al., 2008), we obtain the grading criteria for each factor.

Several methods, such as a fuzzy comprehensive assessment method (Jiang et al., 2008), variable fuzzy sets theory (Chen and Guo, 2006), and the attribute interval recognition theory (Zou et al., 2011) are employed for flood hazard assessment and flood vulnerability assessment.

Recently, we presented a new model for comprehensive flood risk assessment, the set pair analysis-variable fuzzy sets model (SPAVFS) (Zou et al., 2012c), which is based on set pair analysis (SPA) and the variable fuzzy sets (VFS) theory. This model determines the relative membership degree function of VFS by using an SPA method and has the advantages of intuitionist course, simple calculation and good generality application. Its flow chart is shown in Fig. 9.

The flood risk analysis module is made up of the management of risk analysis data, the risk assessment models for flood risk analysis and flood risk maps, and it can show results with a map and chart mode. The specific technical route of this module is as follows:

1. Based on GIS, statistical data and historical information, we collect the precipitation data, elevation data, land use data, social-economic data and so on.

2. Then taking the towns as the basic assessment units, we count out four hazard assessment indexes' characteristic values (see Table 1 and Fig. 10) via the simulation results of hydrodynamic models, including average maximum flow velocity and flood depth, flood submerging range and flood arriving time. Moreover, considering the fact that the weather, terrain and river distribution had a greater impact on flood hazard assessment, we add up the other three hazard assessment indexes, e.g., annual average precipitation, average ground elevation and land use rate. What's more, for flood vulnerability assessment, there are a corresponding six indexes (see Table 2), consisting of population density, industrial output density, agricultural production densities, breeding area percentage, animal density and road network density. Hence, according to the situation of the Jingjiang flood diversion area, we collect data for flood hazard and vulnerability analysis.

3. After the establishment of the flood risk assessment index system and the grading criteria, the flood hazard and vulnerability assessment results can then be obtained by SPAVFS method. Here the flood hazard, vulnerability and risk are divided into five grades, noted as very low, low, medium, high and very high.

4. With the flood hazard and vulnerability assessment results, and the flood risk grade-classification-matrix (Du et al., 2006), we access the corresponding risk grade for each assessment unit. Finally, we are able to carry out the flood risk maps (see Fig. 11) for the Jingjiang flood diversion district.

\subsection{Flood damage estimation}

The final part is the flood damage estimation. First we collect the data of flood ranges. As Fig. 12 shows, affected areas with different depths of water are marked by diverse colors, and we can see the estimation results of each town. At the same time, we can also see the relation of time and damage estimation via the grid-based flood analysis model.

The processing steps of grid-based flood analysis model (see Fig. 13) are as follows:

1. Using the result of the two-dimensional hydrodynamic model, the water depth and the flow velocity are recorded in the nodes, then use the GIS spatial analyst component, IDW (inverse distance weighted) interpolation method to obtain the flood submerge raster.

2. Damages of different aspects, including the loss of houses, industry, affected population, and economic loss (see Table 3), can easily be quantified by a flood disaster evaluation model (Xie, 2011). Its equation is as follows:

$W=\sum_{i} \sum_{j} \sum_{k} \alpha_{i} A_{i j} \eta_{j k}$,

where $i, j, k$ is the index of calculation cell, land use type, and water depth level respectively; $A_{i j}$ is the original output value of the $j$ th land use type in the $i$ th cell; $\eta_{j k}$ is the loss rate of the $j$ th land use type in the $k$ th water depth level. $\alpha_{i}$ is a sign code: (1) when $\alpha_{i}=1$, it means the ith cell needs to calculate the loss; (2) when $\alpha_{i}=0$, it means the ith cell does not need to calculate the loss.

3. By using the Geoprocessing Service (which mentioned in the Sect. 4.4), the flood feature rasters are reclassified by water depth level, and then mixed up with the submerge information by time sequence.

\section{Method benefits and validation}

\subsection{Method benefits}

The method described in this paper was applied to five projects over the past $4 \mathrm{yr}$. It has been playing a substitute 


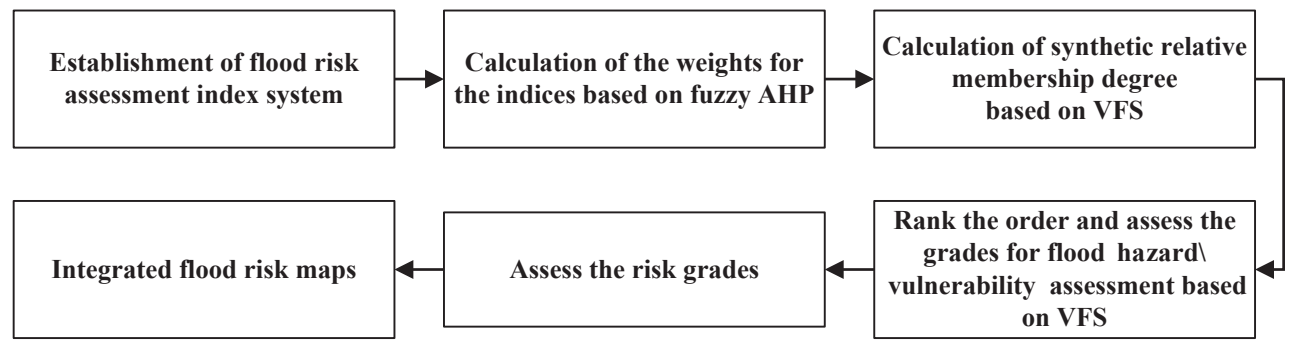

Fig. 9. Flow chart of flood disaster risk assessment.

A

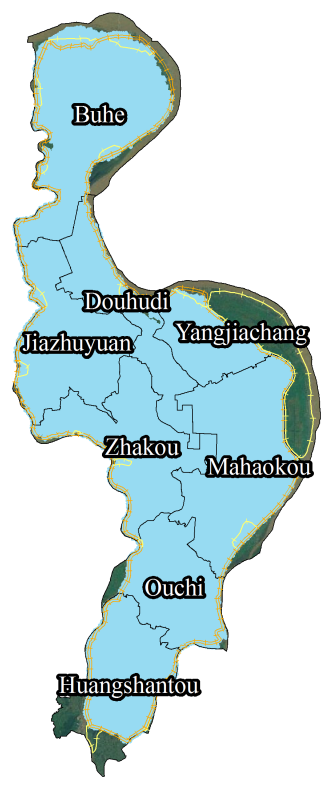

$\mathrm{C}$

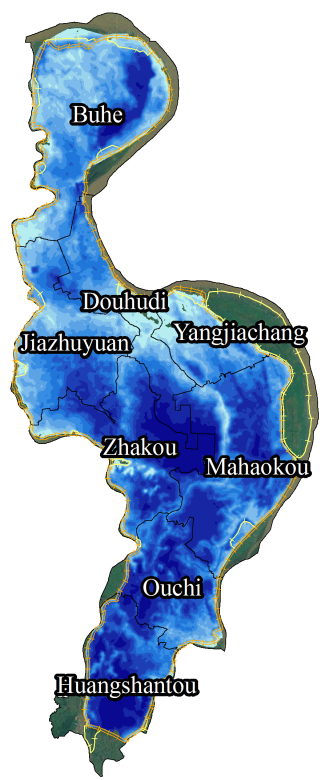

Flood submerging range
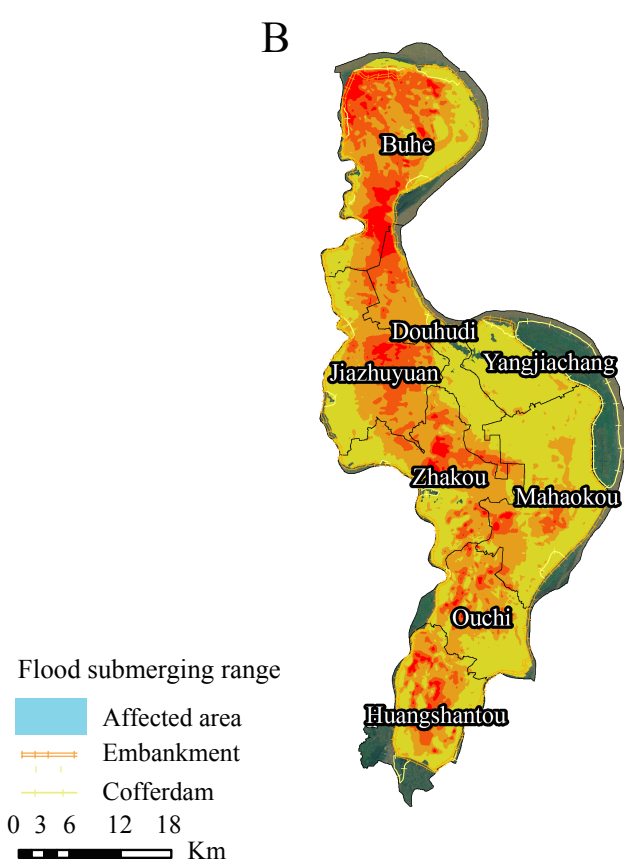

D

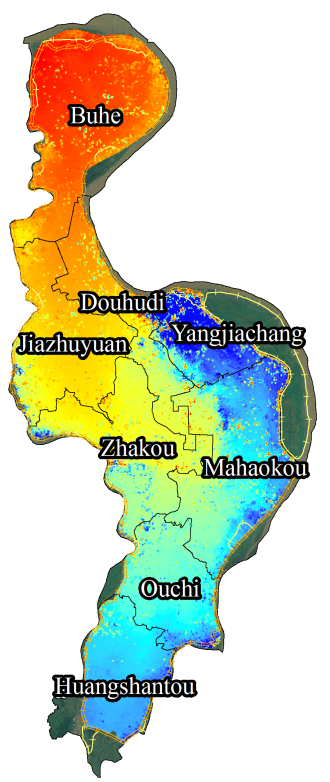

$\Lambda^{\mathrm{N}}$

Flood flow velocity $(\mathrm{m} / \mathrm{s})$

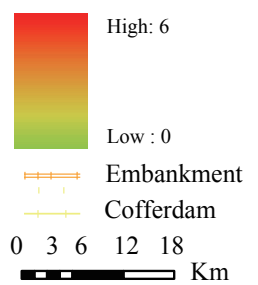

Flood arriving time (min)

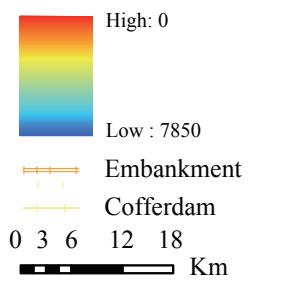

Fig. 10. Four hazard assessment indexes characteristic values from the simulation results of hydrodynamic models: (A) flood submerging range; (B) flood flow velocity; (C) flood water depth; (D) flood arriving time. 
Table 1. Hazard characteristic by analyzing submerged condition.

\begin{tabular}{lrrrrrr}
\hline Town & $\begin{array}{r}\text { Flow } \\
\text { velocity } \\
\left(\mathrm{m} \mathrm{s}^{-1}\right)\end{array}$ & $\begin{array}{r}\text { Flood } \\
\text { depth } \\
(\mathrm{m})\end{array}$ & $\begin{array}{r}\text { Arriving } \\
\text { time } \\
(\mathrm{h})\end{array}$ & $\begin{array}{r}\text { Submerging } \\
\text { range } \\
\left(\mathrm{km}^{2}\right)\end{array}$ & Precipitation & Elevation \\
\hline Buhe & 0.43 & 1.85 & 0 & 177.73 & 1064 & 36.18 \\
Douhudi & 0.3 & 2.3 & 10.41 & 84.61 & 1064 & 33.27 \\
Yangjiachang & 0.04 & 0.7 & 36.66 & 61.35 & 1064 & 33.77 \\
Mahaokou & 0.2 & 3.14 & 37.91 & 169.15 & 1064 & 32.27 \\
Ouchi & 0.28 & 3.25 & 48.74 & 93.01 & 1211 & 32.27 \\
Huangshantou & 0.32 & 3.88 & 59.58 & 89.76 & 1400 & 33.68 \\
Zhakou & 0.35 & 3.45 & 28.33 & 125.75 & 1064 & 32.1 \\
Jiazhuyuan & 0.37 & 2.15 & 15.83 & 128.54 & 1064 & 33.51 \\
\hline
\end{tabular}

Table 2. Vulnerability characteristic within the unit area (e.g., $1 \mathrm{~km}^{2}$ ).

\begin{tabular}{lrrrrrr}
\hline Town & Population & $\begin{array}{r}\text { Road } \\
(\mathrm{m})\end{array}$ & $\begin{array}{r}\text { Industry } \\
\left(10^{4} ¥\right)\end{array}$ & $\begin{array}{r}\text { Agricultural } \\
\left(10^{4} ¥\right)\end{array}$ & Animals & $\begin{array}{r}\text { Breeding } \\
\text { area }\end{array}$ \\
\hline Buhe & 440.86 & 241.17 & 1104.96 & 101.43 & 25.19 & $3.53 \%$ \\
Douhudi & 1520.18 & 425.1 & 3824.32 & 130.13 & 77.79 & $6.01 \%$ \\
Yangjiachang & 393.85 & 100.18 & 1534.6 & 110.01 & 24.58 & $5.56 \%$ \\
Mahaokou & 342.38 & 255.45 & 762.95 & 108.79 & 87.94 & $8.05 \%$ \\
Ouchi & 475.49 & 314.74 & 2539.23 & 106.19 & 62.35 & $20.9 \%$ \\
Huangshantou & 334.16 & 243.76 & 292.55 & 81.38 & 99.65 & $11.92 \%$ \\
Zhakou & 404.1 & 282.33 & 798.59 & 92.34 & 78.42 & $10.48 \%$ \\
Jiazhuyuan & 427.3 & 242.9 & 771.78 & 128.5 & 72.11 & $7.42 \%$ \\
\hline
\end{tabular}
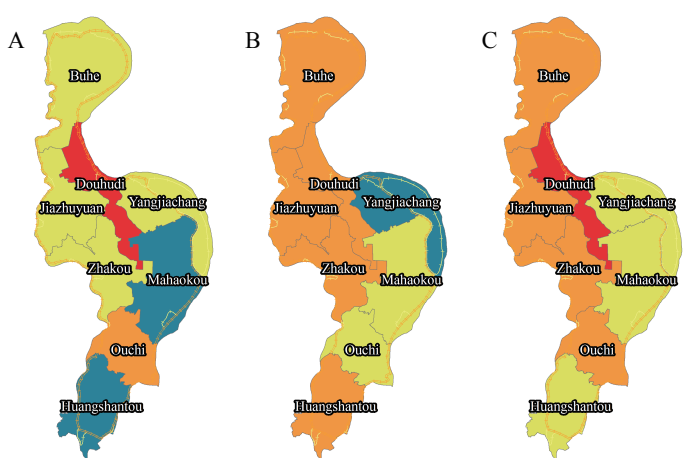

$\stackrel{N}{N}$

Fig. 11. Integrated flood risk maps for the Jingjiang flood diversion district: (A) flood vulnerability grade map; (B) flood hazard grade map; (C) flood risk grade map.

role for existing programmes. Compared with traditional solutions, this subsection identifies and discusses the benefits of our model-driven method.

\subsubsection{Supporting heterogeneity}

By nature, all large systems are heterogeneous. These systems have different purposes, times of implementation, and ages, and it is commonly found that the system landscapes are accretions of different platforms, programming lan- guages, programming paradigms, and even middleware. In the past, traditional solutions attempted to solve the problems of scalability by harmonization, sometimes they worked, but the maintenance cost became incredibly expensive with the expansion of the system (Josuttis, 2009).

In our model-driven method, ESB (see Sect. 4.3) is employed. The idea behind it is that instead of creating and maintaining individual communication channels, each model only has to connect to the bus to be able to connect to all other models. In order to be extended for the larger system, we have identified the research directions related to the technical and organizational rules of implementing a flexible framework. The heterogeneous models are virtually unrelated functional units, but rather loose-coupling spread over interconnected networks.

\subsubsection{Dynamic adaptation of support regarding the needs of the decision-maker}

Dynamic adaptation, which is defined in this paper, means that the system can be flexible and reliable, restructuring to meet the different needs of the decision-maker. Compared to the traditional method, the main advantage of our method is the software life cycle, which at its core consists of phases of design, implementation, integration, and production. Most traditional methods are waterfall-like approaches, i.e., they 


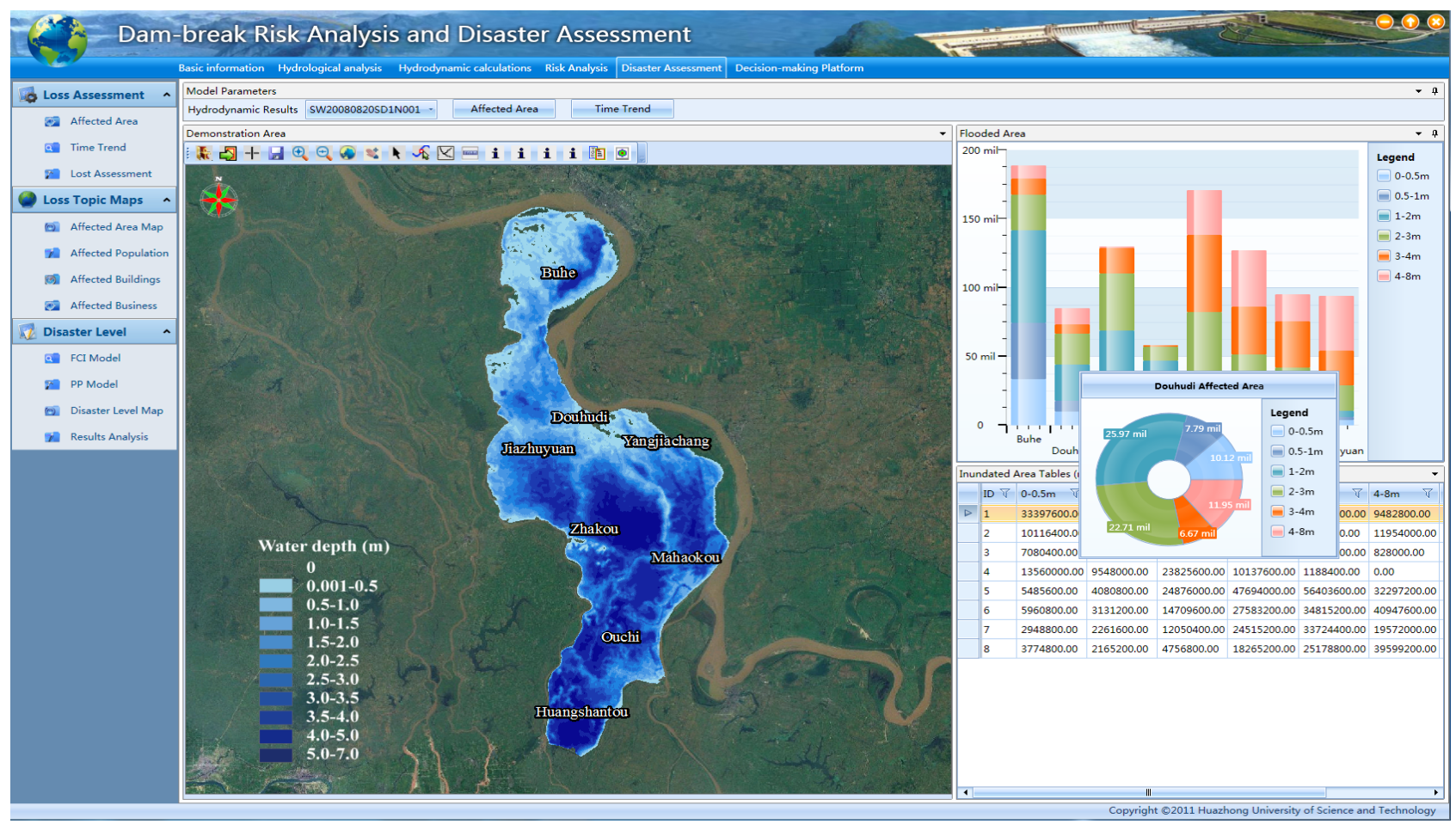

Fig. 12. Interface of submerged condition analysis in quantitative flood damage estimation module.

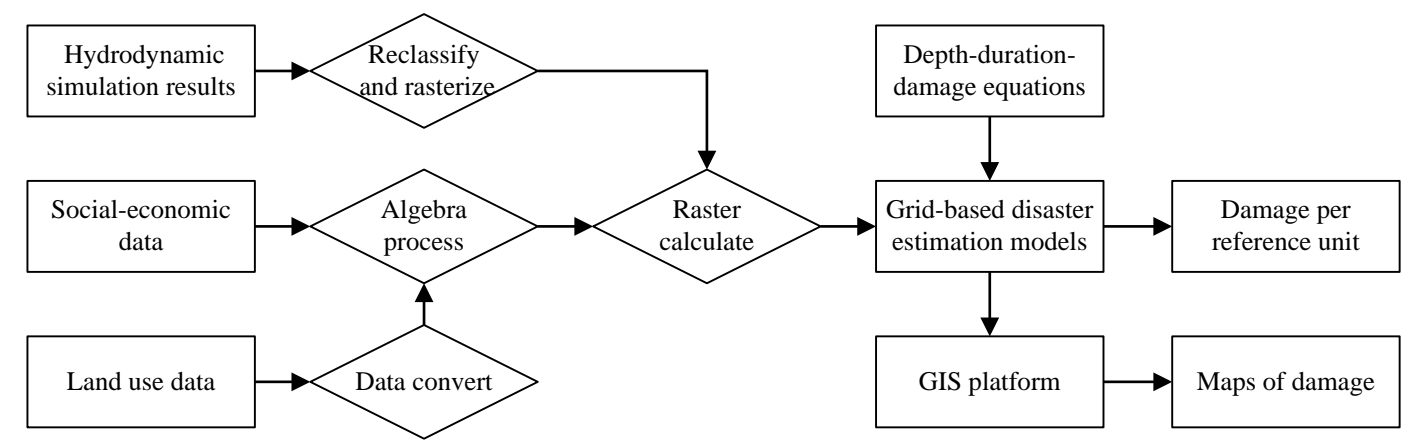

Fig. 13. The process of the flood submerging analyst and flood hazard loss evaluation.

Table 3. The result of the quantitative flood damage estimation module.

\begin{tabular}{lrrrr}
\hline Town & $\begin{array}{r}\text { Affected } \\
\text { houses }\end{array}$ & $\begin{array}{r}\text { Industry } \\
\left(10^{4} ¥\right)\end{array}$ & $\begin{array}{r}\text { Affected } \\
\text { population }\end{array}$ & $\begin{array}{r}\text { Economic } \\
\text { loss }\left(10^{4} ¥\right)\end{array}$ \\
\hline Buhe & 24614 & 7441.73 & 22260.49 & 29931.68 \\
DouhuDi & 37315 & 9032.57 & 9617.81 & 18903.33 \\
Yangjiachang & 4287 & 1464.52 & 6683.63 & 8293.80 \\
Mahaokou & 27484 & 5929.71 & 20300.79 & 26418.28 \\
Ouchi & 17279 & 5737.39 & 9701.07 & 15974.35 \\
Huangshantou & 11768 & 7.67 & 6330.81 & 6545.33 \\
Zhakou & 17574 & 2355.12 & 8649.18 & 11416.63 \\
Jiazhuyuan & 14388 & 2424.80 & 14270.33 & 17021.73 \\
\hline
\end{tabular}

gradually complete the process in one way. It does not work because of requirements as well as contexts changes over time (Josuttis, 2009).

Our method makes the DSS in a continuous-integrated state (see Sect. 3 and Fig. 1). Open library (see Sect. 4.3) can provide the suitable model composition by iterative service development with managers' feedback. New clients are also available at any time through a simple XAML design by practitioners (see Sect. 4.5). Therefore, our method can provide the dynamic adaptation of support regarding the needs of the decision-maker. 
Table 4. Comparison between traditional tight-coupling systems* and MDSS.

\begin{tabular}{lll}
\hline & Traditional tight-coupling systems & MDSS \\
\hline Development efficiency & $\begin{array}{l}\text { Complex development process: } \\
\text { including requirements, design, construction, } \\
\text { integration, testing and de-bugging, } \\
\text { installation and maintenance; }\end{array}$ & $\begin{array}{l}\text { Two-stage development process: } \\
\text { (1) deploy the universal loose-coupling technical prototype; } \\
\text { (2) iteration optimization with } \\
\text { technical-loop and behavioral-loop; }\end{array}$ \\
\hline Distributed integration & $\begin{array}{l}\text { They solve the problems } \\
\text { of scalability by harmonization, } \\
\text { the maintenance cost becomes incredibly expensive; }\end{array}$ & $\begin{array}{l}\text { It provides } \\
\text { flexible integration methods with } \\
\text { open libry based on SOA; }\end{array}$ \\
\hline Emergency needs & $\begin{array}{l}\text { They cannot be provided } \\
\text { within the prescribed time; }\end{array}$ & $\begin{array}{l}\text { It publishes deployable } \\
\text { software at any time by loose-coupling } \\
\text { technical prototype; }\end{array}$ \\
\hline Deployment flexibility & $\begin{array}{l}\text { They provide only } \\
\text { one type or a few similar } \\
\text { types of clients; }\end{array}$ & $\begin{array}{l}\text { It provides flexible } \\
\text { user interfaces with expanded } \\
\text { GIS by WPF and Interface Service; }\end{array}$ \\
\hline Model creditability & $\begin{array}{l}\text { It is difficult to verify } \\
\text { or maintain a single model in } \\
\text { the tight-coupling architecture; }\end{array}$ & $\begin{array}{l}\text { According to the review } \\
\text { from practitioners and managers, models } \\
\text { will be modified to increase the adaptability; }\end{array}$ \\
& $\begin{array}{l}\text { new client will be deployed to verify the model creditability; } \\
\text { automatically loop; }\end{array}$
\end{tabular}

* These traditional systems use some fixed interfaces, tightly integrated data, models, GISs, clients. Therefore, the change of any part will affect the other elements.

\subsubsection{Protection of intellectual property rights}

In traditional object-oriented programs, the models run as plugins, extensions or code block. Illegal software technicians can get the source code by some simple decompiler tools. This is a major hazard of the interdisciplinary cooperation.

In our model-driven method, by using SOA, the web service mode restricts the behavior of user access models. When a user accesses the service, we focus on three aspects of security: (1) authentication, which has to do with verifying an identity. This means finding out who is calling the service. (2) Authorization, which has to do with determining what an identity is allowed to do. this involves checking whether the caller is allowed to call the service and/or see the result. (3) Auditing, which involves recording all security-relevant information, so that we can detect or analyze security holes and attacks. This mechanism ensures that users cannot use the model until they pass the legal validation.

\subsection{Method validation}

In this subsection, we compare the MDSS model with others on a set of criteria. We chose the following methodological framework (Zeng et al., 2007; Chen et al., 2011; Qi and Altinakar, 2011), because it is representative of methods for risk management in some facets. Table 4 shows the comparison.

Feature comparison between our method and other methods shows that our method is an integrated methodology, which ensures the adaptability of the effective loop optimiza- tion mechanism, while other methods focus on one specific issue or a part of the issue.

Zeng et al. (2007) built a GIS-based DSS for assessing the risk of wind damage in forests. The method integrates the models into GIS software (ArcGIS) as a toolbar, which is the most representative method in related fields. However, because the models are integrated in a fixed workflow, the system looks more like a calculator than a DSS. In addition, other problems can be outlined as follows: (1) software development takes a lot of time; (2) this mode is very hard to support the multidisciplinary multi-department collaboration; (3) user interface can not be customized to individual needs, and differences impact the subsequent use of a DSS; (4) it is difficult to verify or maintain a single model.

Two other methods (Chen et al., 2011; Qi and Altinakar, 2011) are similar to that of Zeng et al. (2007). The major difference is that they deploy a standalone application as an extension of ArcGIS under the Windows environment. Therefore, these two methods have the same problem with Zeng et al. (2007).

Superior from other simpler DSS, the most important qualities of MDSS are flexibility and adaptability. In this section, we will analyze a real example (which is described in Sect. 5) with quantitative results to compare MDSS with other DSS.

The decision situations of flood risk management in the Jingjiang flood diversion area are complex and uncertain. There are several basic problems in the implement of such a huge system, which can be outlined as follows: (1) the whole decision-making process is composed of 49 multidisciplinary models; (2) difficulties in joint integration because of the model researchers are distributed across four cities; 
(3) copyright and security issues regarding the use of original data; (4) the ever-changing needs of project managers.

The research team began work with traditional methods from 2007. The whole decision-making process was split into several parts, which were assigned to many groups with synchronized communication once a month. This method was maintained for two years. The decision processes and computer systems were becoming too complex to harmonize or maintain control. For this reason, we present the modeldriven method that accepts heterogeneity and leads to adaptability, and developed a loose-coupling model framework for model integration. Under the new framework, integration of a single model takes from $3 \mathrm{~h}$ to 2 days, and implementation of the whole project took 2 months. The first generation of MDSS has been running in the Jingjiang flood diversion area for three years. During this period, managers changed the decision-making processes five times, and the average maintenance time is 2 weeks. The comparative studies posed above demonstrate that MDSS is efficient, adaptable and flexible.

\section{Conclusions}

Quantitative models embedded in a DSS can help managers make better decisions (Power and Sharda, 2007), and the effectiveness of DSS is enhanced through dynamic adaptation of support regarding the needs of the decision-maker (Bijan et al., 1997). This paper presents a beneficial approach to ensure the adaptability of DSS for flood risk management, and the main innovation is the application of model-driven concepts, which are promising for loose-coupling of GIS and multidisciplinary models.

During the course of the model-driven method, several important issues specific to the implementation effort became apparent and had to be resolved. The service-oriented architecture (SOA) is employed to solve the integration problems. SOA accepts that the only way to maintain flexibility in large distributed systems is to support heterogeneity, decentralization, and fault tolerance (Josuttis, 2009). It is not a specific technology, but a way of thinking. Our model-driven method is a strategy that includes both technical and organizational aspects. Organizationally, we need appropriate processes so that it is clear how to design new solutions and identify new services (see Sect. 3). Technically, we need some infrastructure to provide interoperability (see Sect. 4). In addition, our MDSS is running successfully to manage the flood risk in the Jingjiang flood diversion area, located in central China near the Yangtze River (see Sect. 5). Section 6 demonstrates the benefits of our model-driven method through comparison with some traditional solutions. It demonstrates that MDSS is efficient, adaptable and flexible, and thus has bright prospects of application for comprehensive flood risk assessment.

\section{Appendix A}

\section{MOCSCDE algorithm for hydrology forecasting}

Suppose the optimization is done under the framework of multi-objectivity. If the pre-defined objective functions conflict with each other, then the final optimization results cannot be one individual but a set of individuals who are the socalled non-dominated results. If all the objective functions aim to be minimized, this optimization problem can be defined as follows:

$\min \left\{f_{1}(X), f_{2}(X), f_{M}(X)\right\}$

$X=\left[x_{1}, x_{2}, x_{D}\right]$,

where $M$ is the number of objective functions, $X$ denotes the model parameters, and $f_{i}$ is the $i$ th objective function. In this paper, the objective functions are

$\operatorname{MSLE}=\frac{1}{N} \sum_{i=1}^{N}\left(\ln Q_{i}-\ln \hat{Q}_{i}\right)^{2}$

$\mathrm{M} 4 \mathrm{E}=\frac{1}{N} \sum_{i=1}^{N}\left(Q_{i}-\hat{Q}_{i}\right)^{4}$,

where $N$ is the sample length, $Q_{i}$ denotes the $i$ th observed streamflow value and $\hat{Q}_{i}$ is the $i$ th simulated streamflow value. The flowchart of the proposed algorithm MOCSCDE is shown in Fig. A1.

\section{Appendix B}

\section{Shallow water equations in hyperbolic conservation form}

The classical shallow water equations refer to the formulation of hydrostatic pressure and bottom slope effects and their division between fluxes and source terms. Song et al. (2011a) proposed a formulation of the classical two-dimensional shallow water equation in conservation form:

$$
\frac{\partial U}{\partial t}+\frac{\partial E}{\partial x}+\frac{\partial G}{\partial y}=S,
$$

in which,

$$
\begin{aligned}
U & =\left[\begin{array}{c}
h \\
h u \\
h v
\end{array}\right], \quad E=\left[\begin{array}{c}
h u \\
h u^{2}+g\left(h^{2}-b^{2}\right) / 2 \\
h u v
\end{array}\right], \\
G & =\left[\begin{array}{c}
h v \\
h u v \\
h v^{2}+g\left(h^{2}-b^{2}\right) / 2
\end{array}\right], S=S_{0}+S_{\mathrm{f}} \\
& =\left[\begin{array}{c}
0 \\
g(h+b) S_{0 x} \\
g(h+b) S_{0 y}
\end{array}\right]+\left[\begin{array}{c}
0 \\
-g h S_{\mathrm{f} x} \\
-g h S_{\mathrm{f} y}
\end{array}\right],
\end{aligned}
$$




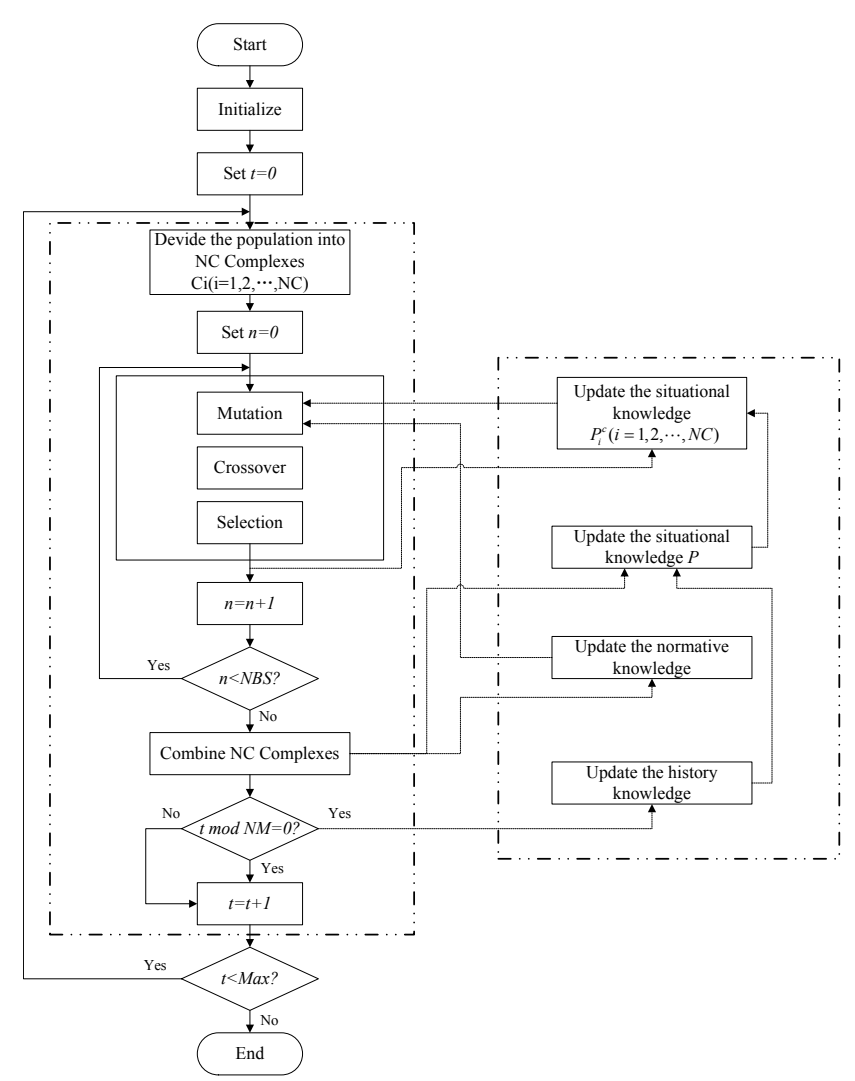

Fig. A1. Flowchart of Multi-objective Culture Shuffled Complex Differential Evolution.

where $h$ is the water depth; $u$ and $v$ are the velocity components in $x$ - and $y$ directions, respectively; $b$ is the bed elevation; $S_{0 x}$ and $S_{0 y}$ are bed slopes in the $x$ - and $y$ directions, respectively, assuming the bed is fixed, i.e., $b=b(x, y)$, then $S_{0 x}=-\partial b / \partial x$ and $S_{0 y}=-\partial b / \partial y ; g$ is the gravity acceleration; $S_{f x}$ and $S_{f y}$ are the friction terms in the $x$ - and $y$ directions, respectively. The friction terms are estimated by the Manning formulae:

$S_{f x}=\frac{n^{2} u \sqrt{u^{2}+v^{2}}}{h^{4 / 3}}, \quad S_{f y}=\frac{n^{2} v \sqrt{u^{2}+v^{2}}}{h^{4 / 3}}$.

Acknowledgements. This work is supported by the State Key Program of National Natural Science of China (No. 51239004), the Special Research Foundation for the Public Welfare Industry of the Ministry of Science and Technology and the Ministry of Water Resources of China (No. 201001080, 201001034, 200901010), National Natural Science Foundation of China (51107047) and the research funds of University and College $\mathrm{PhD}$ discipline of China (No. 20100142110012).

Edited by: P. Tarolli Reviewed by: E. I. Nikolopoulos and two anonymous referees

\section{References}

ArcGIS Resource Center: About the ArcGIS Server 9.3, available at: http://resources.arcgis.com/zh-cn/content/arcgisserver/9. 3/about (last access: 4 January 2013), 2008.

ArcGIS Resource Center: About the ArcGIS Server 9.3, available at: http://resources.arcgis.com/zh-cn/content/arcgisserver/9. 3/about (last access: 4 January 2013), 2008.

Bézivin, J.: In Search of a Basic Principle for Model Driven Engineering, Novatica/Upgrade, 2, 21-24, 2004.

Bijan, F., Mihir, A., and Sameer, V.: Adaptive decision support systems, Decis. Support Syst., 20, 297-315, 1997.

Chen, H., Wood, M. D., Linstead, C., and Maltby, E.: Uncertainty analysis in a GIS-based multicriteria analysis tool for river catchment management, Environ. Modell. Softw., 26, 395-405, doi:10.1016/j.envsoft.2010.09.005, 2011.

Chen, S. and Guo, Y.: Variable fuzzy sets and its application in comprehensive risk evaluation for flood-control engineering system, Fuzzy Optim. Decis. Ma., 5, 153-162, doi:10.1007/s10700-0067333-y, 2006.

Du, J., He, F., and Shi, P.: Integrated flood risk assessment of Xiangjiang River Basin in China, Journal of Natural Disaster, 15, 38-44, 2006 (in Chinese).

Eom, S. B.: Decision Support Systems Research and Reference Disciplines (1970-2001): A Research Guide to the Literature and an Unobtrusive Bibliography with Citation Frequency, Edwin Mellen Press, Lewiston, NY, 2003.

Escuder-Bueno, I., Castillo-Rodríguez, J. T., Zechner, S., Jöbstl, C., Perales-Momparler, S., and Petaccia, G.: A quantitative flood risk analysis methodology for urban areas with integration of social research data, Nat. Hazards Earth Syst. Sci., 12, 2843-2863, doi:10.5194/nhess-12-2843-2012, 2012.

Evers, M., Jonoski, A., Maksimovic, C., Lange, L., Ochoa Rodriguez, S., Teklesadik, A., Cortes Arevalo, J., Almoradie, A., Eduardo Simões, N., Wang, L., and Makropoulos, C.: Collaborative modelling for active involvement of stakeholders in urban flood risk management, Nat. Hazards Earth Syst. Sci., 12, 28212842, doi:10.5194/nhess-12-2821-2012, 2012.

Feng, P., Cui, G. T., and Zhong, Y.: On the evaluation and prediction of urban flood economic loss, J. Hydraul. Eng., 8, 64-68, 2001 (in Chinese).

Gates, B.: Bill Gates Keynote: Microsoft Tech-Ed. 2008 - Developers, available at: http://www.microsoft.com/presspass/exec/billg/ speeches/2008/06-03teched.mspx (last access: 4 January 2013), 2008.

Guo, J., Zhou, J., Qin, H., Zou, Q., and Li, Q.: Monthly streamflow forecasting based on improved support vector machine model, Expert Syst. Appl., 38, 13073-13081, doi:10.1016/j.eswa.2011.04.114, 2011.

Guo, J., Zhou, J., Zhou, C., Wang, G., and Zhang, Y.: Multi-objective optimization for conceptual hydrological models, Advances in Water Science, 23, 447-456, 2012 (in Chinese).

Hu, J., Khalil, I., Han, S., and Mahmood, A.: Seamless integration of depend ability and security concepts in SOA, A feedback control system based framework and taxonomy, J. Netw. Comput. Appl., 34, 1150-1159, doi:10.1016/j.jnca.2010.11.013, 2011.

International Federation of Red Cross and Red Crescent Societies: World disaster report, Oxford University Press, Oxford, 1998. 
Jiang, W., Li, J., Chen, Y., Sheng, S., and Zhou, G.: Risk assessment system for regional flood disaster: principle and method, Journal of natural disaster, 17, 53-59, 2008 (in Chinese).

Josuttis, N. M.: SOA in Practice - The Art of Distributed System Design, O'Reilly Media, Inc., 2009.

Ray, J. J.: A web-based spatial decision support system optimizes routes for oversize/overweight vehicles in Delaware, Decis. Support Syst., 43, 1171-1185, doi:10.1016/j.dss.2005.07.007, 2007.

Li, S., Yu, P., and Sun, S.: Fuzzy Risk Assessment of Flood Hazard Based on Artificial Neural Network for Detention Basin, China rural water and hydropower, 6, 60-64, 2008 (in Chinese).

Li, Y., Gong, J. H., Zhu, J., Ye, L., Song, Y. Q., and Yue, Y. J.: Efficient dam break flood simulation methods for developing a preliminary evacuation plan after the Wenchuan Earthquake, Nat. Hazards Earth Syst. Sci., 12, 97-106, doi:10.5194/nhess-12-972012, 2012.

Liu, Y., Zhou, J. Z., Song, L. X., Zou, Q., Liao, L. and Wang, Y. R.: Numerical modelling of free-surface shallow flows over irregular topography with complex geometry, Applied Math. Model., 37, 9482-9498, doi:10.1016/j.apm.2013.05.001, 2013.

McKinney, D. C. and Cai, X.: Linking GIS and water resources management models: an objectoriented method, Environ. Modell. Softw., 17, 413-425, 2002.

Mehmood, A. and Jawawi, D. N. A.: Aspect-oriented model-driven code generation: A systematic mapping study, Inform. Software Tech., 55, 395-411, doi:10.1016/j.infsof.2012.09.003, 2013.

Merz, B., Kreibich, H., Schwarze, R., and Thieken, A.: Review article "Assessment of economic flood damage", Nat. Hazards Earth Syst. Sci., 10, 1697-1724, doi:10.5194/nhess-10-16972010, 2010.

Power, D. J. and Sharda, R.: Model-driven decision support systems: Concepts and research directions, Decis. Support Syst., 43, 1044-1061, doi:10.1016/j.dss.2005.05.030, 2007.

Qi, H. and Altinakar, M. S.: A GIS-based decision support system for integrated flood management under uncertainty with two dimensional numerical simulations. , Environ. Modell. Softw., 26, 817-821, doi:10.1016/j.envsoft.2010.11.006, 2011.

Schallehn, E., Sattler, K., and Saake, G.: Efficient similarity-based operations for data integration, Data Knowl. Eng., 48, 361-387, doi:10.1016/j.datak.2003.08.004, 2003.

Schinke, R., Neubert, M., Hennersdorf, J., Stodolny, U., Sommer, T., and Naumann, T.: Damage estimation of subterranean building constructions due to groundwater inundation - the GIS-based model approach GRUWAD, Nat. Hazards Earth Syst. Sci., 12, 2865-2877, doi:10.5194/nhess-12-2865-2012, 2012.
Song, L., Zhou, J., Guo, J., Zou, Q., and Liu, Y.: A robust wellbalanced finite volume model for shallow water flows with wetting and drying over irregular terrain, Adv. Water Resour., 34, 915-932, doi:10.1016/j.advwatres.2011.04.017, $2011 \mathrm{a}$.

Song, L., Zhou, J., Li, Q., Yang, X., and Zhang, Y.: An unstructured finite volume model for dam-break floods with wet/dry fronts over complex topography, Int. J. Numer. Meth. Fl., 67, 960-980, doi:10.1002/fld.2397, 2011b.

Wang, X., Zhang, X., and Lai, G.: Over-standard integrated risk analysis of flood control system, J. Hydraul. Eng., 2, 83-87, 2004 (in Chinese).

Watson, A.: A brief history of MDA, upgrade, The European Journal for the Informatics Professional, IX, 7-11, 2008.

Wu, Q., Xu, H., and Zou, X.: An effective method for 3D geological modeling with multi-source data integration, Comput. Geosci., 31, 35-43, doi:10.1016/j.cageo.2004.09.005, 2005.

Xie, T., Zhou, J., Song, L., Wang, Y., and Zou, Q.: Dynamic Evaluation and Implementation of Flood Loss Based on GIS Grid Data, Comm. Com. In. Sc., 228, 558-565, 2011.

Zeng, H., Talkkari, A., Peltola, H., and Kellomaki, S.: A GIS-based decision support system for risk assessment of wind damage in forest management, Environ. Modell. Softw., 22, 1240-1249, doi:10.1016/j.envsoft.2006.07.002, 2007.

Zhao, R.: Watershed Hydrological Modelling, Beijing: ChinaWater Power Press, 109-118, 1984 (in Chinese).

Zou, Q., Zhou, J., Yang, X., He, Y., and Zhang, Y.: A comprehensive assessment model for severity degree of dam failure impact based on attribute interval recognition theory, Journal of Sichuan University (engineering science edition), 43, 45-50, 2011 (in Chinese).

Zou, Q., Zhou, J., Zhou, C., Song, L., Guo, J., and Liu, Y.: The practical research on flood risk analysis based on IIOSM and fuzzycut technique, Appl. Math. Model., 36, 3271-3282, 2012a.

Zou, Q., Zhou, J., Zhou, C., Guo, J., Deng, W., Yang, M., and Liao, L.: Fuzzy risk analysis of flood disasters based on diffusedinterior-outer-set model, Expert Syst. Appl., 39, 6213-6220, doi:10.1016/j.eswa.2011.12.008, 2012b.

Zou, Q., Zhou, J., Zhou, C., Song, L., and Guo, J.: Comprehensive flood risk assessment based on set pair analysis-variable fuzzy sets model and fuzzy AHP, Stoch. Env. Res. Risk A., 27, 525546, doi:10.1007/s00477-012-0598-5, 2012c. 